Original Research Article

\title{
Adjuvant role of testosterone in treatment of schizophrenia and its interaction with combination of first and second generation anti- psychotics, chlorpromazine and risperidone
}

\author{
Tarun Vijaywargia*
}

Department of Pharmacology, Jhalawar Medical College and Associated group of Hospitals, Jhalawar, Rajasthan, India

Received: 17 May 2018 Accepted: 29 May 2018

*Correspondence to: Dr. Tarun Vijaywargia, Email: tarunvijaywari76@ yahoo.com

Copyright: (C) the author(s), publisher and licensee Medip Academy. This is an openaccess article distributed under the terms of the Creative Commons Attribution NonCommercial License, which permits unrestricted noncommercial use, distribution, and reproduction in any medium, provided the original work is properly cited.

\begin{abstract}
Background: There is great controversy about role of male sex steroid, testosterone, in mental disorders like schizophrenia. This study assessed the effectiveness of testosterone in schizophrenic patients and probes how it modulates the action of combination of first and second generation anti-psychotic medications (Chlorpromazine + Risperidone) both of which are very commonly used anti-psychotic agents in clinical psychiatric practice.

Methods: It Is randomized, double-blind, Clinical study performed in Indian schizophrenic patients (new cases) in the Department of psychiatry from Feb 2003 to March 2004. Patients twelve (12) patients aged 20 to 60 years diagnosed schizophrenics according to ICD-10 Criteria who visited in outpatient department of psychiatry during study period. 12 Patient was treated with combination of oral Chlorpromazine 200mg BD + oral Risperidone $2 \mathrm{mg}$ BD, half of the 12 patients also received single dose of testosterone $100 \mathrm{mg}$ intramuscularly with abovementioned treatment. Measure How symptomatology in schizophrenic patients affected is measured by applying various validated psychiatric scales like Brief psychiatric Rating Score (BPRS), Scale for assessment of positive symptom(SAPS), and Scale for Assessment of Negative Symptoms (SANS).

Results: Single dose of Testosterone $100 \mathrm{mg}$ administered initially by I.M. route potentiated the reduction level in negative symptoms of schizophrenia by $119 \%$ in patients receiving oral Chlorpromazine $200 \mathrm{mg}$ along with oral Risperidone $4 \mathrm{mg} /$ day.

Conclusions: In this study, Testosterone potentiated the effects of combination of oral Chlorpromazine $100 \mathrm{mg}$ BD + Risperidone $2 \mathrm{mg}$ BD, on general psychotic manifestations, positive symptoms and negative symptoms of schizophrenia, assessed on BPRS, SAPS and SANS scoring scales, however the effect is most pronounced in negative symptomology of schizophrenia.
\end{abstract}

Keywords: Chlorpromazine, Risperidone, Schizophrenia, Testosterone

\section{INTRODUCTION}

The definition of mental disorder guides distinguishing pathology from what is normal .In DSM-IV TR criteria mental disorder is defined as a clinically significant behavioral or psychological syndrome or pattern that occurs in an individual and that is associated with present distress or disability or a significant increase in suffering, death, pain, disability or an important loss of freedom. ${ }^{1}$ Schizoprenia is generally a chronic disorder that during active phase presents with delusions, hallucination, disorganized speech and disorganized behavior (known as positive symptoms) or negative symptoms such as flat affect, Avolition and Alogia. The diagnosis of schizophrenia is made when these symptoms of active disease present for more than 1 month. ${ }^{2}$ People with 
schizophrenia are profoundly sensitive to their immediate social environment. In India poor outcomes of this chronic disease is due to poor understanding of disease, patient and relative education, social stigma and less treatment options that may have long term therapeutic impact once administered for e.g. depot haloperidol deconoate. ${ }^{3}$ The basic Pathophysiology of schizophrenia is still obscure but pharmacological interventions study suggests that neurotransmitter system involved in it. It is well known fact that is also utilized in clinical practice that blockade of dopamine receptors of D2 type in mesolimbic area controls positive symptoms of schizophrenia but actually produce or augment negative symptoms. This study gives the clue that there is dopaminergic hyperactivity in mesolimbic area that produces positive symptoms but hypoactivity in mesocortical area that produces negative symptoms of schizophrenia (first generation agents are less effective in controlling negative symptoms due to D2 receptor blockade). ${ }^{4}$ Recently several lines of evidence implicate excitatory amino acid glutamate in the Pathophysiology of schizophrenia. This hypothesis is based on the clinical observation that administration of Ketamine a NMDA antagonist produces a clinical syndrome which is indistinguishable from schizophrenia. This hypothesis concludes that Hypofunction of glutamatergic neurotransmission in mesocortical and mesolimbic area produces cognitive (memory and learning) and possibly affective, negative and positive symptoms of schizophrenia. ${ }^{5}$ Testosterone is the principle sex hormone that has varied effects on psychology and behavior of the individual. ${ }^{6}$ Physiologically testosterone increase learning in stressful situation or enhance mathematical and spatial thinking but in high dose (more than 1000mg testosterone / week) it can produce delusions and it occur in the absence of manic episodes. ${ }^{7-9}$ The two major issues that prompted us to choose testosterone as an agent that may have some impact on the symptomology of schizophrenia is firstly in brain approximately $0.03 \%$ of testosterone converted into estradiol which in various clinical studies found to have anti-schizophrenic effects and potentiated the effect of standard anti-psychotic drugs. ${ }^{10,11}$ Secondly the Glutamatergic neurotransmission in brain is enhanced by an endogenous neuromodulator, Hydrogen Sulfide, the rate of production of which is increased by testosterone administration, as reported in animal studies. ${ }^{12}$ Some clinical observations as made by Strauss et al, reported improved mental states in 6 of 8 male patients with schizophrenic illness treated with various doses of dehydroisoandrosterone (steroid molecule chemically related to testosterone) over several weeks. ${ }^{13}$ Sex differences in the clinical expression of schizophrenia have also been observed. For example, women with schizophrenia have a higher prevalence of auditory hallucinations than men. ${ }^{14}$ Women with schizophrenia have been described as "hallucinatory, illusionary", (positive symptom predominance) with symptoms mimicking affective disorders, whereas men tend to become "dull, autistic" and have an amotivational syndrome (negative symptom predominance) with loss of organization and regulation. ${ }^{15}$ These molecular, cellular and clinical observations prompted us to organize a systematic clinical study that will probe in the therapeutic efficacy of testosterone in schizophrenic patients and the way it modulate the action of combination of first generation(chlorpromazine) and second generation(Risperidone) antipsychotic drug. The objective of this study was to investigate the use of testosterone esters as an adjuvant to conventional treatment of schizophrenia, using a randomized, double-blind, controlled (conventional treatment only) clinical study and also exploring how testosterone interacts with first and second generation anti-psychotic drugs.

\section{METHODS}

Patients diagnosed as schizophrenic with no associated disease and who fall into all exclusion and inclusion criteria for the clinical interaction study.

Semi structured proforma of patient consisting of

- $\quad$ Biodata of patient

- History of illness

- Mental status and sex status

- General and physical examination notes

- Follow-up scales

- $\quad$ Adverse effect profile

Parameters/scales of diagnosis and grading the psychosis 3 types - as under (Source: Lyerly SB: Handbook of Psychiatric Rating Scale, Ed. 2, National Institute of Mental Health, Bethesda, 1973)

- $\quad$ BPRS (Brief Psychiatric Rating Scale) - 1

- $\quad$ SAPS (Scale of Assessment of Positive Symptoms) 2

- SANS (Scale of Assessment of Negative Symptoms)-3

ICD-10 Classification for Diagnosis of Schizophrenia omit (- 4) (Source: WHO: The ICD-10 classification of mental and behavioral disorders: Clinical Descriptions and Diagnostic Guidelines, WHO, Geneva, 1992)

Drugs and their dosage form. It includes:

- Tablet Chlorpromazine 100mg - Sun Pharmaceuticals, Ahmedabad

- Tablet Risperidone (SIZODON) 2mg - Sun Pharmaceuticals, Ahmedabad.

- Injection testosterone esters (Sustanon) 100mg, $1 \mathrm{ml}$ ampoule - Infer Pharmaceuticals, Bombay.

$2 \mathrm{ml}$ syringes, needles ( $24 \mathrm{G})$, spirit, cotton

Sphygmomanometer (Diamond), stethoscope (Littman), weighing machine.

Patient signed informed consent form. 


\section{Method of human exploratory clinical trial}

- Objective: To study the interaction of Testosterone with anti-psychotic medication chlorpromazine and Risperidone in schizophrenic patients.

- Type of study: Randomized, double-blinded, and controlled (conventional treatment only).

- Sample size: The study was conducted on 12 schizophrenic patients.

- Study center: The study was conducted in collaboration with department of psychiatry M.Y. Hospital, Indore and Department of Pharmacology, M.G.M. Medical College, Indore between Feb 2003 to March 2004 and followed the Good Clinical Practice guidelines ( $\mathrm{ICH})$

- Grouping of sample population: It depends upon therapeutic intervention. Following are groups:

Table 1: Grouping of sample population.

\begin{tabular}{|c|c|c|}
\hline $\begin{array}{l}\text { Study } \\
\text { group }\end{array}$ & $\mathbf{n}$ & $\begin{array}{l}\text { Treatment given } \\
\text { (drug, formulation, route, dose, } \\
\text { frequency and duration) }\end{array}$ \\
\hline $\mathrm{E}$ & 6 & $\begin{array}{l}\text { Oral tab. CPZ } 100 \mathrm{mg} \text { Twice a day }+ \\
\text { oral tab. Risperidone } 2 \mathrm{mg} \text { twice a } \\
\text { dayx } 28 \text { days. }\end{array}$ \\
\hline $\mathrm{F}$ & 6 & $\begin{array}{l}\text { Oral tab. CPZ 100mg Twice a day }+ \\
\text { Oral tab. Risperidone } 2 \mathrm{mg} \text { twice a } \\
\text { dayx } 28 \text { days + (SUSTANON) } 100 \mathrm{mg} \text {, } \\
1 \mathrm{ml} \text { ampoule single i.m dose }\end{array}$ \\
\hline
\end{tabular}

Follow up

The follow up of patients was done in the OPD on regular/periodic basis (every $7^{\text {th }}$ day from start of study). Those cases who failed to come at the trial center were given follow-up at their homes.

\section{Design of study}

This trial was conducted in collaboration with department of psychiatry, in M.Y.H Hospital, Indore. The cases of schizophrenia are selected according to "selection criteria" which is mentioned below:

\section{Inclusion criteria}

Age-20 to 60 years schizophrenic patients diagnosed by ICD-10 diagnostic criteria.

\section{Exclusion criteria}

- Patients who have any other physical or mental illness than schizophrenia,

- Pregnant or nursing women

- Decreased hepatic or renal function.

\section{Conduct of trial}

The antipsychotic medications used in this study is chlorpromazine and Risperidone, the dose decided for Chlorpromazine was $100 \mathrm{mg}$ twice daily and for Risperidone $2 \mathrm{mg}$ twice daily. The testosterone ester preparation used was sustanon $100 \mathrm{mg}$ and administered as a single intramuscular dose at the initiation of study. The total duration of study was 28 days. The protocol and informed consent were approved by the regional ethics committee. Written informed consent was obtained for all patients. Patients are randomized according to Random Table and given Treatment by an independent contributor who did not know the nature and protocol of study to ensure proper double blinding.

As per the design of study stipulated fixed dose of antipsychotic medication were given orally for 28 days uninterruptedly in the OPD of psychiatry. The patients were instructed to come at OPD every $7^{\text {th }}$ day along with relatives for interrogations regarding medications and symptomology of illness during the follow-up phase of the study.

The duration of follow-up was done every $7^{\text {th }}$ day till the end of study (i.e. 28 days).

The diagnosis of schizophrenia is made by ICD-10 classification, while the alteration in signs and symptoms of the illness following medication was monitored weekly by BPRS, SAPS, and SANS psychiatric rating scales. During follow-up along with the assessment of psychiatric symptoms, adverse reactions of administered drugs are also watched and along with that patients certain physiological parameter like blood pressure, pulse and weight are also monitored.

These follow-up scales and criteria of ICD-10 are satisfied by conducting interview with patient and their relatives. Each symptom and its severity are assessed by putting some questions in front of patient and members of his/her family. The presence of psychiatrist facilitates diagnosis and assessment of severity of illness.

\section{Outcome and statistical analysis}

Primary efficacy outcome measure was reduction of score of different psychiatric scoring scales BPRS (Brief Psychiatric Rating Scale), SAPS (Scale for assessment of positive symptoms, and SANS (Scale for Assessment of Negative Symptoms Paired ' $t$ ' test is used for determining level of significance ( $\mathrm{p}$ value) of intervention.

\section{RESULTS}

It is evident from the Table 2 that Risperidone $2 \mathrm{mg}$ and Chlorpromazine $100 \mathrm{mg}$ orally per day for 3 weeks caused reduction in psychiatric symptoms by $19 \%$ to $22 \%$ in different psychiatric scales. 
Table 2: Effect of chlorpromazine $100 \mathrm{mg}$ orally per day and risperidone $2 \mathrm{mg}$ orally per day on four different psychiatric scoring scales in schizophrenic patients.

\begin{tabular}{|c|c|c|c|c|c|c|}
\hline \multirow[b]{2}{*}{ Patient No. } & \multicolumn{2}{|l|}{ BPRS } & \multicolumn{2}{|l|}{ SAPS } & \multicolumn{2}{|l|}{ SANS } \\
\hline & $\begin{array}{l}\text { Pre- } \\
\text { treatment } \\
\text { score }\end{array}$ & $\begin{array}{l}3^{\text {rd }} \text { week post } \\
\text { CPZ + RIS } \\
\text { treatment score }\end{array}$ & $\begin{array}{l}\text { Pre- } \\
\text { treatment } \\
\text { score }\end{array}$ & $\begin{array}{l}3^{\text {rd }} \text { week post } \\
\text { CPZ + RIS } \\
\text { treatment score }\end{array}$ & $\begin{array}{l}\text { Pre- } \\
\text { treatment } \\
\text { score }\end{array}$ & $\begin{array}{l}3^{\text {rd }} \text { week post } \\
\text { CPZ + RIS } \\
\text { treatment score }\end{array}$ \\
\hline 01 & 65 & 45 & 99 & 60 & 113 & 74 \\
\hline 02 & 57 & 42 & 119 & 96 & 69 & 60 \\
\hline 03 & 82 & 67 & 143 & 126 & 104 & 74 \\
\hline 04 & 70 & 60 & 124 & 113 & 43 & 39 \\
\hline 05 & 53 & 43 & 108 & 76 & 67 & 61 \\
\hline 06 & 66 & 52 & 100 & 86 & 103 & 89 \\
\hline Tot. & 393 & 309 & 693 & 557 & 499 & 397 \\
\hline$\%$ red. in score & $21.37 \%$ & & $19.62 \%$ & & $20.44 \%$ & \\
\hline
\end{tabular}

Table 3: Effect of chlorpromazine $100 \mathrm{mg}$ orally per day, Risperidone $2 \mathrm{mg}$ orally per day + initial dose of Testosterone intra-muscularly (Sustanon 100mg) on three different Psychiatric scoring scales in schizophrenic patients.

\begin{tabular}{|lllllll|}
\hline $\begin{array}{l}\text { Patient } \\
\text { no. }\end{array}$ & $\begin{array}{l}\text { Pre- } \\
\text { treatment } \\
\text { score }\end{array}$ & $\begin{array}{l}\mathbf{3}^{\text {rd }} \text { week post CPZ } \\
\text { + RIS + TES } \\
\text { treatment score }\end{array}$ & $\begin{array}{l}\text { SAPS } \\
\text { Pre- } \\
\text { treatment } \\
\text { score }\end{array}$ & $\begin{array}{l}\mathbf{3}^{\text {rd }} \text { week post CPZ } \\
+ \text { RIS + TES } \\
\text { treatment score }\end{array}$ & $\begin{array}{l}\text { Pre- } \\
\text { treatment } \\
\text { score }\end{array}$ & $\begin{array}{l}\mathbf{3}^{\text {rd }} \text { week post CPZ } \\
\text { + RIS + TES } \\
\text { treatment score }\end{array}$ \\
\hline 01 & 99 & 74 & 173 & 120 & 120 & 72 \\
\hline 02 & 70 & 39 & 132 & 99 & 71 & 27 \\
\hline 03 & 65 & 33 & 108 & 77 & 64 & 26 \\
\hline 04 & 70 & 46 & 107 & 74 & 115 & 70 \\
\hline 05 & 90 & 59 & 148 & 100 & 115 & 64 \\
\hline 06 & 86 & 62 & 151 & 103 & 576 & 318 \\
\hline Tot. & 480 & 313 & 819 & 573 & $44.80 \%$ & \\
\hline $\begin{array}{l}\text { \% red. in } \\
\text { score }\end{array}$ & $34.70 \%$ & & $30.00 \%$ & & & 59 \\
\hline
\end{tabular}

Table 4: Effects of testosterone administered as Initial single dose 100mg intramuscularly on three different psychiatric scales in schizophrenic patients receiving oral risperidone $2 \mathrm{mg}+\mathrm{CPZ}$ 100mg daily for 3 weeks.

\begin{tabular}{|c|c|c|c|c|c|c|c|c|c|c|}
\hline & \multirow{2}{*}{$\begin{array}{l}\text { Treatment } \\
\text { Group }\end{array}$} & \multicolumn{3}{|c|}{$\begin{array}{l}\% \text { Reduction in BPRS } \\
\text { Score }\end{array}$} & \multicolumn{3}{|c|}{$\begin{array}{l}\% \text { Reduction in SAPS } \\
\text { Score }\end{array}$} & \multicolumn{3}{|c|}{$\begin{array}{l}\% \text { Reduction in SANS } \\
\text { Score }\end{array}$} \\
\hline & & $\begin{array}{l}\% \\
\text { reduction }\end{array}$ & $\begin{array}{l}\text { 't' } \\
\text { value }\end{array}$ & $\begin{array}{l}P \\
\text { value }\end{array}$ & $\begin{array}{l}\% \\
\text { reduction }\end{array}$ & $\begin{array}{l}\text { 't' } \\
\text { value }\end{array}$ & $P$ value & $\begin{array}{l}\% \\
\text { reduction }\end{array}$ & $\begin{array}{l}\text { 't' } \\
\text { value }\end{array}$ & $\begin{array}{l}P \\
\text { value }\end{array}$ \\
\hline $\mathrm{E}$ & $\begin{array}{l}\text { Risperidone } \\
2 \mathrm{mg}+\mathrm{CPZ} \\
100 \text { only } \\
(\text { Control) }\end{array}$ & $21.37 \%$ & 9.15 & $<0.001$ & $21 \%$ & 5.34 & $<0.01$ & 20.44 & 3.11 & $<0.05$ \\
\hline $\mathrm{F}$ & $\begin{array}{l}\text { Risperidone } \\
2 \mathrm{mg}+\mathrm{CPZ} \\
100 \mathrm{mg}+ \\
\text { Testo }\end{array}$ & $34 \%$ & 17.72 & $<0.001$ & $30 \%$ & 10.35 & $<0.001$ & $44.8 \%$ & 6.23 & $<0.01$ \\
\hline$E \& F$ & $\begin{array}{l}\text { Effect of F } \\
\text { over E }\end{array}$ & $59 \%$ & 6.45 & $<0.001$ & $42 \%$ & 2.87 & $<0.05$ & $119 \%$ & 2.23 & $<0.05$ \\
\hline
\end{tabular}

It is evident from the Table 3 that CPZ 100mg, Risperidone $2 \mathrm{mg}$ orally per day for 3 weeks and initial dose of testosterone intra-muscularly caused reduction in psychiatric symptoms by $35 \%$ (As reflected in BPRS).
However, reduction in positive symptoms by $30 \%$ (As reflected in SAPS) is less than negative symptoms (45\%) (As reflected in SANS). 
It is evident from the Table 4 that addition of testosterone single dose $100 \mathrm{mg}$ IM to Risperidone $2 \mathrm{mg}$ /day orally and CPZ 100mg / day orally for 3 weeks caused potentiation in the degree of improvement in overall psychiatric symptoms as measured on BPRS. However, the improvement was less $(42 \%)$ in positive symptoms and more $(119 \%)$ in negative symptoms.

Table 5: Effect of CPZ, risperidone and testosterone in schizophrenic patients on BPRS, SAPS, and SANS.

\begin{tabular}{|c|c|c|c|c|c|c|c|c|c|c|}
\hline \multirow[b]{2}{*}{ Treatment group } & \multirow[b]{2}{*}{$\mathbf{N}$} & \multicolumn{3}{|c|}{$\begin{array}{l}\text { BPRS (Total of group) } \\
\text { Max. Score }=648\end{array}$} & \multicolumn{3}{|c|}{$\begin{array}{l}\text { SAPS (Total of group) } \\
\text { Max. Score = } 1050\end{array}$} & \multicolumn{3}{|c|}{$\begin{array}{l}\text { SANS (Total of group) } \\
\text { Max. Score }=720\end{array}$} \\
\hline & & 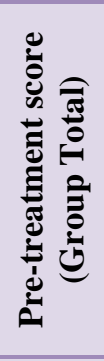 & 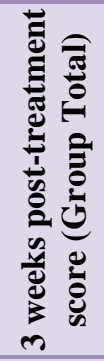 & 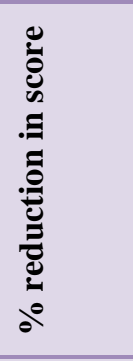 & 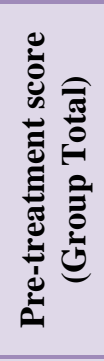 & 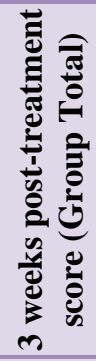 & 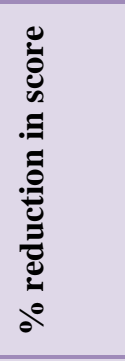 & 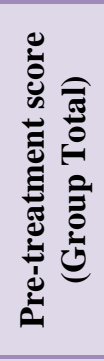 & 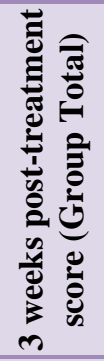 & 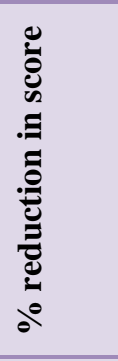 \\
\hline CPZ 100mg + Ris. $2 \mathrm{mg}$ only & 6 & 393 & 309 & $21.37 \%$ & 693 & 547 & $21.06 \%$ & 499 & 397 & $20.44 \%$ \\
\hline $\begin{array}{l}\text { CPZ 100mg + Ris } 2 \mathrm{mg}+ \\
\text { Testosterone }\end{array}$ & 6 & 480 & 313 & $34.7 \%$ & 819 & 573 & $30.0 \%$ & 576 & 318 & $44.8 \%$ \\
\hline
\end{tabular}

It is evident from the Table 5 that $\mathrm{CPZ}$ and Risperidone both reduce the psychiatric manifestations in Schizophrenia the later more than the former and their effects are augmented by Testosterone, especially on Negative symptoms.

Of the 12 patients randomized, there were no dropouts, all patients complied with treatment. No patient had taken any other treatment than given in this trial. Statistical analysis was done for all 12 patients' primary outcome measures. Out of 12 patients included in study 6 were female and other 6 were male. Average mean age of females was 36 year and males mean age was 40 years. All patients completed the study according to protocol. Base line and after treatment score on different psychiatric scale of all treatment group was given in Table 5. No significant adverse effects were reported in any patient in any treatment group. In the study, Chlorpromazine + Risperidone treated group was compared with Testosterone + Chlorpromazine + Risperidone treated group. It was observed in the scale which measures overall psychiatric manifestations i.e. BPRS (Brief Psychiatric Rating Scale) that improvement in schizophrenic patients by testosterone + chlorpromazine + Risperidone treatment of about $90 \%$ was over the improvement as found only in Chlorpromazine + Risperidone treated patients. However, the improvement was only $41 \%$ in positive symptoms as was evident by SAPS (i.e. Scale for Assessment of Positive Symptoms) and $119 \%$ in Negative symptoms as was evident by SANS (i.e. Scale for Assessment of Negative Symptoms) in these patients of schizophrenia. It is inferred that when testosterone hormone was combined with chlorpromazine + Risperidone there was observed a significant augmentation in the improvement level more in negative than in positive symptoms of schizophrenia.

\section{DISCUSSION}

All psychiatric trials always have a subjective element inherent in them. In this study every effort has been made to overcoming this shortcoming by use of standardized psychiatric scales and questionnaires. Moreover, the gross difference between treatment group and control group outcome (mainly negative symptoms, which are more common among males) safely predict that testosterone esters can be used in schizophrenia as adjuvant to antipsychotic treatment. In Korea KO YH et al, conduct double blind RCT study with testosterone gel and antipsychotic medications and found improvement in negative symptoms of schizophrenia in 30 schizophrenic males. ${ }^{16}$ This study in Department of Psychiatry, Korea University College of Medicine, Seoul, South Korea further supports the finding we get in our study in 2003-2004.The postulated mechanism which brought this effect on symptomology may be favourable effect of testosterone on glutamatergic neurotransmission even in such low doses and frequency, combined with its metabolite effect (Estradiol) in brain. The effect of testosterone on aggressiveness seems to be insignificant in the study that may be due to use of low dose and effect of antipsychotic medications. ${ }^{17}$ Thus current study proves positively the adjuvant role of testosterone in the treatment of negative symptoms of schizophrenia and it interact favorably with first or second generation anti-psychotic medications. Availability of testosterone esters as parentral depot (IM) preparation sustaining its action for one month, makes its administration in schizophrenic patients easier and meeting the administration compliance. From Pharmacoeconomic point of view the cost of commercial preparation is also bearable by the patient as frequency of administration is one /month. Further research can be done 
for optimizing the dose of testosterone for schizophrenia negative symptom retrogression and improving socialization and make schizophrenic patients more functional and interactive in day to day activities. Minimization of testosterone dose by conducting studies with lesser doses of testosterone can further enhance their value in treatment of schizophrenia.

\section{CONCLUSION}

In the study chlorpromazine treated group was compared with chlorpromazine + Risperidone + Testosterone treated group. The negative symptoms of the illness underwent suppression by $115 \%$ over the same effect of chlorpromazine + Risperidone by the addition of testosterone to the combination. The positive symptoms of the illness were suppressed by testosterone insignificantly.

Funding: No funding sources

Conflict of interest: None declared

Ethical approval: The study was approved by the Institutional Ethics Committee

\section{REFERENCES}

1. American psychiatric association. Diagnostic and statistical manual of mental disorders, 4th edition.' Text revision. Washington, DC, American psychiatric association. 2000.

2. Zimmerman M, Mattia JI. Psychiatric diagnosis in clinical practice: is comorbidity being missed? Compr Psychiatry. 1999;40:182.

3. Grover S, Avasthi A, Chakrabarti S, Bhansali A, Kulhara P. Cost of care of schizophrenia: a study of Indian out-patient attenders. Acta Psychiatr Scand. 2005;112:54-63.

4. Kahn RS, Devis KL. New developments in dopamine and schizophrenia. In Psychopharmacology: The fourth generation of progress (ed.) F.E. Bloom and DJ Kupter. Raven Press, New York; 1995:1193-1204.

5. Coyle JT, Tsai G, Goff D. Converging evidence of NMDA receptor hypofunction in the Pathophysiology of schizophrenia. Ann J Y Acad Sci. 2003;1003:318.

6. Griffin JE, Ojeda SR. Text book of Endocrine Physiology, New York, Oxford University Press; 1996;1017-1018.

7. Shores TJ, Miesegaes G. Testosterone in utero and at birth dictates how stressful experience will affect learning in adulthood. Proc Natl Acad Sci USA .2002 Oct 15;99(21):13955-60.

8. Bart JM, Van Uljmen H, Belindra HOF, Marc J, Mol TM, Hans Van der Boom, et al, effect of androgens on growth of right and left cerebral hemispheres and also growth of brain cells primarily used in thinking, behavioral and neuron. Biology. 1988;49:344.

9. Pope HG Jr, Katz DL. psychiatric and medical effects of anabolic-androgenic steroid use. Arch Gen Psychiatry. 1994;51:375.

10. Kulkarni J, Riedel A, de Castella AR, Fitzgerald PB, Ralfe TJ, Taffe J, et al. A clinical trial of adjunctive estrogen treatment in women with schizophrenia. Arch Women Ment Health. Nov 2002;5(3):99-104.

11. Decastella A, Granger ABDA. The effect of schizophrenia on sex hormones blood levels. Psychiatric Services. 2002;53:600-3.

12. Eto K, Kimura H. The production of hydrogen sulfide is regulated by testosterone and S-Adenosyl-Lmethionine in mouse brain. J Neurochem. 2002 Oct;83(1):80-6.

13. Strauss EB, Sands DE, Robinson AM, Tindall WJ, Stevenson WAH. British Medical Journal 08/1952; 2(4775):64-6. Source: PubMed.

14. Goldstein JM, Link BG. Gender and the expression of schizophrenia. J Psychiatry Res. 1988;22:141-55.

15. Lewine R. Schizophrenia: an amotivational syndrome in men. Can J Psychiatry. 1985;30:316-8.

16. Ko YH, Lew YM, Jung SW, Joe SH, Lee CH, Jung $\mathrm{HG}$, et al. Short-term testosterone augmentation in male schizophrenics: a randomized, double-blind, placebo-controlled trial, J Clin Psychopharmacol. 2008 Aug;28(4):375-83.

17. Malone DA Jr. Pharmacological therapies of anabolic androgenic steroid addiction. In: Miller NS, Gold MS, editors. Pharmacological Therapies for Drug and Alcohol Addictions. New York: Marcel Dekker Inc; 1995:227-237.

Cite this article as: Vijaywargia T. Adjuvant role of testosterone in treatment of schizophrenia and its interaction with combination of first and second generation anti-psychotics, chlorpromazine and risperidone. Int J Basic Clin Pharmacol 2018;7:124752. 